\title{
Editorial
}

\section{Dilemas éticos en la pandemia}

Los dilemas éticos en la pandemia de la COVID-19 (enfermedad causada por el coronavirus SARS-CoV-2) han sido múltiples, abarcan prácticamente todos los tópicos y se inician desde el origen mismo de la pandemia. Se han barajado muchas hipótesis sobre el comienzo y el origen de la COVID-19, pues el tema no es menor ya que se trata de un virus que hasta el momento ha cobrado la vida de más de cinco millones de personas. Desde su probable origen en animales, entre ellos los murciélagos, se han mencionado muchas otras posibilidades que incluyen un virus producido en el laboratorio y que eventualmente pudo salir de allí por accidente, hasta otras hipótesis que generarían un dilema ético mayor. Es probable que nunca llegamos a establecer con certeza absoluta que fue lo que pasó, por lo que el debate ético sobre este tema es mas que todo un ejercicio teórico, que no sobra.

Superado este punto sigue el debate sobre si el anuncio del comienzo se demoró, lo que habría impedido tomar medidas tempranas que eventualmente hubieran permitido contener el brote. La Organización Mundial de la Salud (OMS) recibió el primer informe oficial el 31 de diciembre de 2019. Investigaciones posteriores demostraron que la agencia china identificó 179 casos en la provincia de Wuhan en diciembre de 2019 y una revisión de 76.253 registros de enfermedades respiratorias ocurridas en los dos meses previos no identificó casos adicionales que pudieran ser ocasionados por la COVID-19.

Con esos datos se puede concluir que no existieron demoras importantes cuestionables éticamente, la OMS una vez recibió la notificación actuó también con rapidez, tomando medidas que se inician el 9 de enero de 2020 con el anuncio de la existencia de una nueva enfermedad en China, la declaratoria de emergencia de salud pública global el 31 de enero y culminan con la declaratoria de la pandemia el 11 de marzo de 2020. Por su parte el virus fue rápidamente identificado y codificado en China y compartida la información en enero de 2020, lo que abrió el camino para la elaboración de vacunas.

Una vez iniciada la pandemia y en el afán por contener su rápida expansión la medida empleada por la mayoría de las naciones fue la de las cuarentenas estrictas. Sin la menor duda, esta medida buscaba un fin bueno, pero tuvo consecuencias económicas y sociales devastadoras, especialmente para las gentes de menores recursos, profundizando las inequidades preexistentes, efecto que no pudo ser evitado a pesar del enorme esfuerzo realizado por los gobiernos al otorgar subsidios económicos extraordinarios a la población mas vulnerable.

Mirando hacia atrás es válido preguntarse si la forma en que se implementaron inicialmente las cuarentenas con la prohibición hasta de salir a la calle, fue exagerada y eventualmente pudieran haberse logrado resultados similares con cuarentenas focalizadas, distanciamiento social y evitando las concentraciones de gente. En este dilema vale la pena profundizar, para que tengamos elementos que nos permitan actuar de la mejor manera en próximas ocasiones. Me aventuro a pronosticar que la población mundial difícilmente acatará nuevas cuarentenas estrictas generales.

Ante la situación que planteaba la enfermedad fue evidente la necesidad de contar con tratamientos y vacunas que permitieran enfrentarla efectivamente. Fuimos testigos de toda clase de tratamientos propuestos con los más variados medicamentos, algunos productos de observaciones casuales, otros de resultados en pequeños grupos de pacientes, la gran mayoría sin la rigidez científica necesaria. La OMS y la Organización Panamericana de la salud OPS desarrollaron siete criterios que se deberían cumplir para el uso de medicamentos e intervenciones en esta emergencia: 1 . No existe ningún tratamiento de eficacia 
comprobada. 2. No es posible iniciar ensayos clínicos inmediatamente. 3. Se dispone de datos que proporcionan un apoyo preliminar de la eficacia y la seguridad de la intervención, al menos de estudios de laboratorio o en animales, y el uso de la intervención fuera de ensayos clínicos ha sido sugerido por un Comité Científico asesor debidamente calificado, sobre la base de un análisis favorable de los riesgos y beneficios. 4. Las autoridades competentes del país y un comité de ética debidamente calificado han aprobado dicho uso. 5 . Se dispone de recursos adecuados para garantizar que los riesgos puedan minimizarse. 6 . Se obtiene el consentimiento informado del paciente. 7. Se monitorea el uso de emergencia de la intervención y los resultados se documentan y se comparten oportunamente con la comunidad médica y la comunidad científica. Desafortunadamente muchos ensayos no se acogieron a este marco ético, especialmente en los comienzos de la pandemia.

Análisis aparte merece el tema de las vacunas, pues en tiempo récord se desarrollaron cerca de 200 posibles vacunas, muy rápido las autoridades sanitarias autorizaron ensayos clínicos de emergencia para varias de ellas y progresivamente han autorizado el uso de emergencia de unas pocas, en base a los resultados de los ensayos clínicos. Pero este, que es uno de los logros importantes de la ciencia, no ha estado exento de cuestionamientos éticos, especialmente relacionados con la protección de los sujetos de investigación y de la población general. El proceso usual para el desarrollo de una vacuna puede tardar de 10 y hasta 15 años desde la fase exploratoria inicial, hasta tener lista su fabricación masiva luego del proceso de aprobación. En contraste las primeras vacunas para COVID-19 se lograron en cerca de doce meses, con la suma de muchos esfuerzos, que incluyeron autorización para fusionar Fase 1 y Fase2, reducción del número de individuos requeridos en cada fase y abreviación de tiempos de aprobación, entre otros.

Afortunadamente luego de cerca de 7.500 millones de dosis aplicadas en 184 países, se puede decir con absoluta certeza que las vacunas aprobadas hasta ahora son seguras y efectivas. Desafortunadamente, otra es la historia con la infinidad de medicamentos que se probaron para la COVID-19 de manera mucho menos rigurosa que en el caso de las vacunas, en que casi todos resultaron totalmente ineficaces. La conclusión obvia es que las medidas éticas que buscan proteger a los sujetos de investigación y a la población general se justifican plenamente.

Superada la etapa de contención, cuando el número de enfermos graves que requirieron soporte ventilatorio en unidades de cuidado intensivo, en los diferentes picos que ha tenido esta pandemia, la disponibilidad de recursos frente a la demanda, planteo el dilema sobre la asignación justa de los recursos disponibles. Sobre este punto inicialmente se propusieron diferentes métodos: asignar por el orden de llegada, de manera que quien primero llega primero se atiende, hasta agotar la disponibilidad, privilegiando a los más jóvenes, desechando a los viejos y a quienes tuvieran discapacidades o enfermedades avanzadas o terminales, mediante sorteos, etc. Muy temprano las principales autoridades bioéticas fijaron su posición en este punto con una gran coincidencia entre todas ellas. Los recursos deben asignarse en primera instancia, a quienes tienen mejores posibilidades de superar el episodio actual, sin tener en cuenta otras consideraciones. Para ello se recomendó que los hospitales crearan comités para realizar dicha asignación, constituidos por personal diferente al encargado de la atención directa de los pacientes. Si luego de ello persistía una demanda que superaba los recursos disponibles, se podrían utilizar criterios adicionales, como los propuestos inicialmente, siempre y cuando las reglas que se aplicarían estuvieran claras para todos.

También el principio de justicia se invocó para garantizar el acceso a los servicios de las personas mas vulnerables y mas pobres. Desde muy temprano se comenzó a observar que las poblaciones mas pobres y los grupos marginados tenían las tasas mas altas de enfermedad y muerte. Varios estudios muestran que la mortalidad puede ser el doble en los estratos mas pobres con relación a los estratos mas altos. En Estados Unidos la pandemia afectó más a los negros, latinos e indígenas que a la población blanca, que se manifiesta por un índice de hospitalización ajustado por edad entre 4 y 5 veces mas alto. 
En el caso de las vacunas, en noviembre de 2021 en la mayoría de los países del primer mundo se han aplicado mas de 150 dosis por 100 habitantes, mientras que varios países africanos tienen menos de 2 dosis por cada 100 personas y el promedio de esa región apenas es de 10 dosis por 100 personas. Los esfuerzos que se han realizado para una distribución mas justa de las vacunas, como el mecanismo COVAX liderado por la OMS, claramente ha sido insuficientes. Cabe preguntarse si ante una situación tan grave para la humanidad no hubieran debido levantarse las patentes de las vacunas para permitir su producción masiva a muy bajos costos para proteger a toda la población.

En las últimas semanas se han anunciado dos medicamentos que parecen tener una eficacia alta para reducir los casos severos o desenlaces fatales, cuando se administran tempranamente. Se trata de Molnupiravir ${ }^{\circledR}$ de la compañía Merck y más recientemente el Paxlovid $^{\circledR}$ de Pfizer. Ambos son orales y para tratamiento ambulatorio. Ambas compañías han anunciado que lo venderán a precios muy bajos para naciones pobres, Merck en $105 \mathrm{y}$ Pfizer en 95 países. Sin duda es un paso importante, que contrasta con lo ocurrido con las vacunas, pero ¿es suficiente?

Las más recientes discusiones éticas giran en torno a la obligatoriedad de la vacunación. Demostrada la efectividad y la seguridad de las vacunas se comenzó a plantear la posibilidad de su obligatoriedad, inicialmente en algunos grupos como los trabajadores de la salud, especialmente quienes atienden directamente pacientes en los hospitales. Algunos han pensado que se debe ir más allá y que la vacunación debe ser obligatoria para toda la población, como sucede hace años con muchas vacunas. Recientemente Austria optó por ordenar la cuarentena obligatoria para los no vacunados, en un esfuerzo por promover la vacunación. Sin embargo, ha surgido en el mundo entero una fuerte oposición a estas medidas impositivas, alegando que vulneran las libertades individuales. Este movimiento que privilegia las libertades individuales sobre el interés colectivo nos coloca ante una discusión ética de gran importancia para la salud pública, ya que desde esta mirada se llega a posiciones tan radicales que afirman que la libertad individual es un bien superior a cualquier otro. Este debate ético apenas comienza y tendrá consecuencias sociales y políticas, que afectarán necesariamente las decisiones en salud, tanto las relacionadas con la COVID-19, como otras muchas.

Este repaso probablemente deja algunos de los dilemas éticos sin mencionar, pero demuestra que esta pandemia ha puesto en evidencia muchas falencias de nuestros sistemas de salud, ha profundizado inequidades y ha invitado a una reflexión ética profunda. Simultáneamente, es justo resaltar el éxito que significa haber desarrollado por primera vez en la historia vacunas efectivas en un tiempo tan corto, producto de diversas tecnologías, como también lo es reconocer el formidable esfuerzo, sacrificio y entrega del personal de salud en todo el mundo.

\section{Roberto Esguerra Gutiérrez}

Médico, especialista en Medicina Interna y Medicina Nuclear

Master del American College of Physicians

Profesor Clínico Titular de ética Médica en la Universidad de los Andes 